\title{
Improvement of Competence Students Through the Implementation of Problem Based Instruction on Laboratory of Building Materials' Course
}

\author{
Nurmi Frida Dorintan B.P. \\ Engineering Faculty \\ The State University of Surabaya \\ Surabaya, Indonesia \\ dorintbert@gmail.com
}

\begin{abstract}
This research is a classroom action research to students of Building Technique Education the State University of Surabaya. Subjects were 38 students who programmed the course of laboratory building materials. The research objective is to improve the competence of students, including cognitive, psychomotor and affective through the implementation of teaching based problems. Teaching is planned so that students are actively engaged and active to accomplish something on their own, or guided, and conducted in three cycles with the subject matter: 1) testing of bricks; 2) testing of tile materials, and 3) testing of ceramics. Indicators of success in cognitive and psychomotor aspects of competence can be achieved when $\mathbf{7 5 \%}$ of all students obtained a score of at least 75 . And the affective aspect is achieved when $75 \%$ of all students were on a scale of 4 and 5. The results showed that: 1) cognitive competence of students in cycle 1 was obtained by $39.47 \%$, amounting to $57.89 \%$ cycle 2 , and cycle 3 amounted to $76.32 \%$. It means in the third cycle of the expected cognitive competency has been achieved, that is more than $75 \%$ of the students have achieved a minimum score of $75 ; 2$ ) psychomotor competence in the form of performance tests show that, in cycle 1 was obtained $55.26 \%$, $68.42 \%$ for cycle 2 and cycle 3 amounted to $78.95 \%$. That is, in the third cycle of learning has reached a psychomotor competencies expected because more than $75 \%$ of the students have achieved a minimum score of $75 ; 3)$ affective competencies derived from the Likert scale observation shows that in cycle 1 was obtained $60.53 \%, 71.05 \%$ for cycle 2 and cycle 3 amounted to $81.58 \%$. That is, in the third cycle of learning subjects building materials laboratory has achieved the expected results because more than $\mathbf{7 5 \%}$ the number of students has reached a scale at least 4. The conclusion of this study are: problem-based instruction includes practice solving problems and providing measures for solving problems can increase student competency either cognitive, psychomotor, and affective on course materials laboratory building with the subject material testing bricks, tiles and ceramics.
\end{abstract}

Keywords-problem based instruction, laboratory building materials, cognitive competence, competence psychomotor, affective competencies

\section{INTRODUCTION}

Building materials laboratory course is compulsory for students of technical education building, which requires competence in learning achievement. Obstacles and problems based on observations during the teaching and discussion with members of the teaching team, the learning laboratory building materials, have not achieved the student competency, particularly in completing the testing of materials accurately and correctly. This condition affects not achieved competencies expected because less understood independently testing materials.

Data from study 47 students in the course of building materials laboratory showed that, as much as 3 students $(6.38 \%)$ received a $\mathrm{D}$ (does not pass), which got a $\mathrm{C}$ as many as 15 students $(31.91 \%)$, which gets the value of B by 23 students (48.93\%), which got an A as 6 students (12.77\%).

The situation described above is a challenge for the team lecturer laboratory building materials to make every effort to improve the competence of students, so as to achieve mastery learning. Based on the results of the reflection of the team lecturer building materials testing, the indicators are not achieving the learning objectives that are caused by various factors.

The problem now, how to condition and implementing learning laboratory course building materials that can encourage the students to quickly understand and interpret the material testing. This understanding as a basis for calculation which is sorely needed in the field of construction through the application of learning that can improve student competency.

One effort that can be made to the above objectives is the implementation of more innovative teaching methods to improve student learning achievement by training to solve a problem. These learning activities will encourage the emergence of student motivation and independence. It is necessary providing learning tools in the form of units of lecture events, teaching materials, activity sheet problem solving and evaluation sheets.

Efforts to improve the learning process by implementing on problem-based teaching should be carried out for the achievement of competence in the subject building materials laboratory. Problem Based Instruction expected application can help students in solving problems related to the testing of building materials is good and true, while expected to achieve competence in testing of building materials that are needed later on in the world of work. 
Based on the terms described above, then the problem of research are:"How to increase the competence of students after implementation of Problem Based Instruction in Course Materials Laboratory in the Department of Civil Engineering Unesa?"

\section{BASIC THEORY}

\section{A. Building Materials Competence Students in the Course of Building Materials Laboratory}

Laboratory' course is an engineering science courses that have competency standards be able to explain the properties and functions of various types of materials, and are able to explain the basics of testing materials and techniques to understand the nature of the material.

The introduction of the materials used for the building in terms of the nature of mechanics, physics and chemistry, as well as processing or manufacturing process. Discussion material that needs to be understood by the students include: 1) materials precarious, 2) materials brick, 3) wood (species and wood processing), 3) the process of making a binder hydraulic, 4) the process of making bricks and conblock, etc. The general objective to be achieved, among others: provide guidance and train students on how physical testing construction materials, and able to carry out their own testing.

To meet the standards of competence of students in completing the course of building materials laboratory, need to be developed learning and assessment that is capable of measuring the competence of each student. Understanding and mastery of the science of building materials largely determines a person's success in developing competence.

The term "competency" refers to the ability of learning capability and is the result of one's learning (Gagne, 1958 in the Azhar Arsyad, 2002: 30-31). Gagne, Briggs, and Wager mean that competence is organizing learning outcomes and experiences that are generally contained in motor skills. There are three important dimensions in the performance of motor skills, namely: (1) smooth rough opponent, (2) continuous discrete opponent, (3) open bight bight opponent covered. (Gagne, 1985 in the Azhar Arsyad, 2002: 128). So as to apply the motor skills that will be used in part of education in schools and a more fundamental about how to develop skills with a marvelous free hand and thoughtfully. Someone develop motor skills through observation or design ideas they always bring.

Detailed competency can be defined as the ability to include the realm of knowledge (cognitive), skills (psychomotor) and attitudes (affective) which is reflected in the ability to act and think. Understanding of the three domains are:

1. Cognitive domains related to students' thinking skills such as knowledge of low level until the level is high. The thought process at a low level just a process of remembering or memorizing. The higher the thinking, will be more complex and require a higher reasoning ability.

2. Affective sphere remains the domain associated with the behavior and events related to attitudes, interests, and personality traits of students.
3. Psychomotor domains associated with motor skills (movement) students. Psychomotor term includes all deliberate human movement. The characteristics of such behavior is a concrete movement patterns can be seen, intentional (desired) and carried out by humans and are considered as part of the educational curriculum objectives. (Mulyati, 2003: 26-30). In connection with the concept of competency, student success in completing the study on laboratory course of building materials is a condition in which was the fulfillment of a requirement levels of cognitive, psychomotor and affective, reflected the ability of individuals that leads to the standard of excellence as a result of the learning process. To declare that a learning process can be successful, if the planned objectives can be achieved.

\section{B. Problem Based Instruction on Course of Building Materials Laboratory}

Problem Based Instruction is a useful learning to stimulate thinking in problem-oriented situation, including learning how to learn. (Ibrahim and Nur, 2000: 2) The role of teachers in the model Problem Based Instruction is presenting problems, ask questions, facilitating the investigation and dialogue. Even more important is that teachers do scafolding, a framework of support that enrich the inquiry and intellectual growth. Problem Based Instruction can not happen without teachers develop classroom environment that allows the exchange of ideas openly.

Problem Based Instruction consists of presenting to the students, a situation that is authentic and meaningful issues that can make it easy for students to carry out the investigation and inquiry. Developers Problem Based Instruction gives the characteristics of this teaching model as follows (Krajcik, Blumenfeld, Mark and Soloway, 1994).

1. Submission of questions or problems: Problem Based Instruction organize teaching around the questions and issues that are important socially and personally meaningful for students. They propose an authentic reallife situations, avoiding simple answers, and allow for a wide variety of solutions to the situation.

2. Focusing on linkages between disciplines: the problem to be investigated have been completely real, so in solving the problems of the students review many aspects

3. The investigation authentic: Problem Based Instruction requires students undertake an investigation to find a solution to a real authenticity to the real problems, analyze and define problems, develop hypotheses and make predictions, collecting and analyzing information, conducting experiments, making inferences and drawing conclusions. Investigation methods are used, depending on the problem being studied.

4. Generate Products: Problem Based Instruction should be able to produce specific products in the form of real work and the demonstration that describes or represents a form of settlement of the problems found. Product may be a transcript of the debate as to the lesson "roots and wings," the report or in the form of a physical model. 
5. Cooperation: Problem Based Instruction characterized as students collaborate with each other, most often in pairs or small groups. Cooperate to provide ongoing motivation to be involved in complex tasks and increase opportunities for shared inquiry, a dialogue to develop skills and thinking.

\section{Hypothesis Actions}

"If the Problem Based Instruction in the course of building materials laboratory applied appropriately, it can increase student competency of Building Technical Education, Civil Engineering Department, Faculty of Engineering"

\section{METHODOLOGY OF RESEARCH}

\section{A. Location and Time Research}

This research was conducted at the Department of Civil Engineering, Faculty of Engineering Unesa in odd semester of academic year 2013/2014. Data collection was conducted in August 2014 until October 2014.

\section{B. Subject and Object Research}

This study uses the subject of the action (principal subject) that 38 students of Building Technical Education, which is programmed course building materials laboratory. Subject broadcaster is lecturer building materials laboratory. Whereas the object of this research is the application of learning Problem Based Instruction.

\section{Research Methods}

References used in the Classroom Action Research is a model Kemmis and MC Taggart. Steps models such as the following picture.

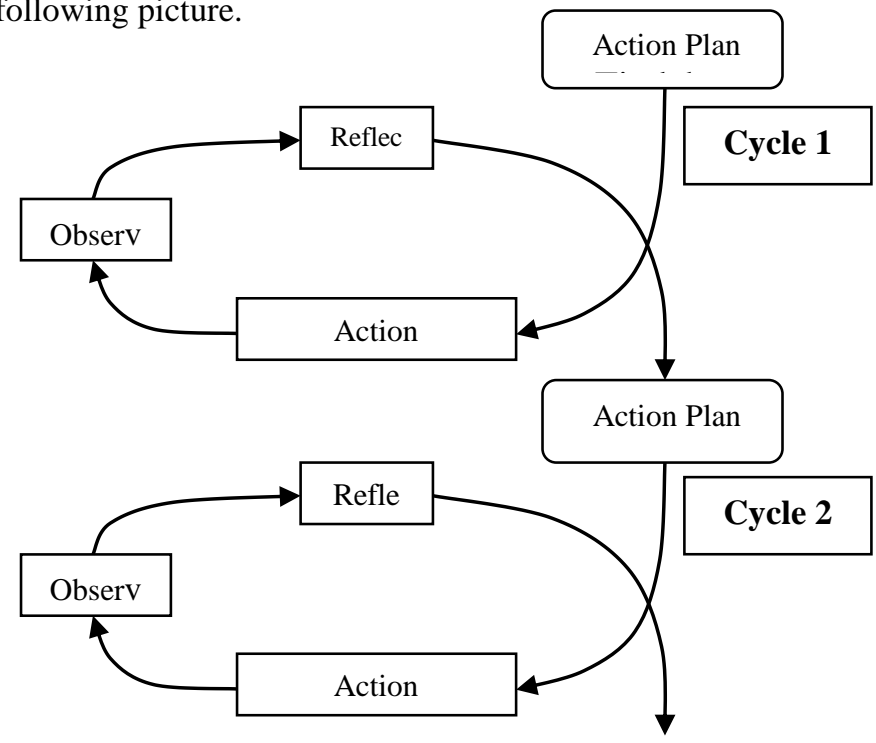

Fig 1. Step Classroom Action Research, a Model Kemmis dan M.C Taggart (Source: Kember, 2000)

\section{Methods of Data Collection}

This study uses the instrument: (1) an instrument competency, include: tests cognitive competencies of student, sheets observations on competence performance (psychomotor), sheet observation of competence affective student, (2) observation sheet activities of lecturers presenting Problem Based Instruction on course building materials laboratory

Competency tests were analyzed using the criteria required that $75 \%$ of the students master the material tests or obtain a minimum score of 75 . competency tests conducted in each cycle, if the student's understanding achieved as required, then the cycle will be completed action.

\section{RESULT AND DISCUSSION}

\section{A. Results of Research}

1. Cognitive Competence of Student. Cognitive competence of student learning outcomes related to intellectual indicated by the value obtained after completing the test. Cognitive competence of students after applied Problem Based Instruction can be seen in the following table.

Table 1. Frequency Distribution of Student Cognitive Competence-Test Scores On Application of Problem Based Instruction Cycle to Cycle

\begin{tabular}{|r|c|c|c|c|c|r|}
\hline \multirow{2}{*}{$\begin{array}{c}\text { Score } \\
\text { Interval }\end{array}$} & \multicolumn{2}{|c|}{ Cycle 1 } & \multicolumn{2}{c|}{ Cycle 2 } & \multicolumn{2}{c|}{ Cycle 3 } \\
\cline { 2 - 7 } & Frequency & \% & Frequency & \% & Frequency & \% \\
\hline $0-30$ & 2 & 5,26 & 0 & 0,00 & 0 & 0,00 \\
\hline $31-54$ & 8 & 21,05 & 4 & 10,53 & 3 & 7,89 \\
\hline $55-74$ & 13 & 34,21 & 12 & 31,58 & 6 & 15,79 \\
\hline $75-89$ & 13 & 34,21 & 16 & 42,11 & 21 & 55,26 \\
\hline $90-100$ & 2 & 5,26 & 6 & 15,79 & 8 & 21,05 \\
\hline Number & 38 & 100,00 & 38 & 100,00 & 38 & 100,00 \\
\hline
\end{tabular}

Table 2. Recapitulation of Student Cognitive Competence On Application of Problem Based Instruction Cycle to Cycle

\begin{tabular}{|l|c|c|c|c|c|c|}
\hline \multirow{2}{*}{ Competence } & \multicolumn{2}{|c|}{ Cycle 1 } & \multicolumn{2}{c|}{ Cycle 2 } & \multicolumn{2}{c|}{ Cycle 3 } \\
\cline { 2 - 7 } & Frequency & \% & Frequency & \% & Frequency & \% \\
\hline Not Competent & 23 & 60,53 & 16 & 42,11 & 9 & 23,68 \\
\hline Competent & 15 & 39,47 & 22 & 57,89 & 29 & 76,32 \\
\hline Number & 38 & 100,00 & 38 & 100,00 & 38 & 100,00 \\
\hline
\end{tabular}

Criteria for achievement of competence is a score $\geq 75$. That is, the students are said to have competence when it got a score of at least 75 . In the table indicated that the percentage of competencies in cycle 3 with the implementation of Problem Based Instruction reach $76.32 \% \geq 75 \%$. It shows that most of the students have managed to achieve competence, as many as 29 students from 38 students. While students are not competent in cognitive aspects are 9 students or by $23.68 \%$. 
2. Psychomotor Competence of Student. Psychomotor assessment obtained from the observation sheet psychomotor performance. Psychomotor competency of students in cycles per cycle of the implementation of Problem Based Instruction can be seen in the following table.

Table 3. Frequency Distribution of Student Psychomotor Competence Performance Scores On Application of Problem Based Instruction Cycle to Cycle

\begin{tabular}{|c|c|c|c|c|c|c|}
\hline \multirow{2}{*}{$\begin{array}{c}\text { Score } \\
\text { Interval }\end{array}$} & \multicolumn{2}{|c|}{ Cycle 1 } & \multicolumn{2}{c|}{ Cycle 2 } & \multicolumn{2}{c|}{ Cycle 3 } \\
\cline { 2 - 7 } & Frequency & \% & Frequency & \% & Frequency & \% \\
\hline $0-30$ & 1 & 2,63 & 0 & 0,00 & 0 & 0,00 \\
\hline $31-54$ & 3 & 7,89 & 4 & 10,53 & 0 & 0,00 \\
\hline $55-74$ & 13 & 34,21 & 8 & 21,05 & 8 & 21,05 \\
\hline $75-89$ & 18 & 47,37 & 20 & 52,63 & 19 & 50,00 \\
\hline $90-100$ & 3 & 7,89 & 6 & 15,79 & 11 & 28,95 \\
\hline Number & 38 & 100,00 & 38 & 100,00 & 38 & 100,00 \\
\hline
\end{tabular}

Table 4. Recapitulation of Student Psychomotor Competence On Application of Problem Based Instruction Cycle to Cycle

\begin{tabular}{|l|c|c|c|c|c|c|}
\hline \multirow{2}{*}{ Competence } & \multicolumn{2}{|c|}{ Cycle 1 } & \multicolumn{2}{c|}{ Cycle 2 } & \multicolumn{2}{c|}{ Cycle 3 } \\
\cline { 2 - 7 } & Frequency & \% & Frequency & \% & Frequency & \% \\
\hline Not Competent & 17 & 44,74 & 12 & 31,58 & 8 & 21,05 \\
\hline Competent & 21 & 55,26 & 26 & 68,42 & 30 & 78,95 \\
\hline Number & 38 & 100,00 & 38 & 100,00 & 38 & 100,00 \\
\hline
\end{tabular}

On the table can be seen that the percentage of psychomotor competencies in cycle 3 with the implementation of Problem Based Instruction reached $78.95 \% \geq 75 \%$. It shows that most of the students have managed to achieve competence, as many as 30 students from 38 students. While students are not competent in aspects psikomotornya there are 8 students or by $21.05 \%$.

3. Affective Competence of Student. Affective competencies of students gained from the observation sheet affective. Affective competencies in learning Problem Based Instruction can be observed through the attitudes and behavior of students in learning activities individually or in groups. Affective competencies of students cycle to cycle can be seen in the following table.

Table 5. Frequency Distribution of Student Affection Competence-Affection Scale On Application of Problem Based Instruction Cycle to Cycle

\begin{tabular}{|c|c|c|c|c|c|c|}
\hline \multirow{2}{*}{ Scale } & \multicolumn{2}{|c|}{ Cycle 1 } & \multicolumn{2}{c|}{ Cycle 2 } & \multicolumn{2}{c|}{ Cycle 3 } \\
\cline { 2 - 7 } & Frequency & $\%$ & Frequency & $\%$ & Frequency & $\%$ \\
\hline 1 & 0 & 0.00 & 0 & 0,00 & 0 & 0.00 \\
\hline 2 & 7 & 18.42 & 5 & 13.16 & 0 & 0.00 \\
\hline 3 & 8 & 21.05 & 6 & 15.79 & 7 & 18.42 \\
\hline 4 & 18 & 47.37 & 17 & 44.74 & 18 & 47.37 \\
\hline 5 & 5 & 13.16 & 10 & 26.32 & 13 & 34.21 \\
\hline Number & 38 & 100,00 & 38 & 100,00 & 38 & 100,00 \\
\hline
\end{tabular}


contained in one cycle into consideration to make improvements in cycle 2. Improvements were made, among others, to motivate students to read the first learning device, in order to understand the problems of a given faculty.

In cycle 2, the test scores of cognitive competence of students at the interval of 0 to 74 , there are 16 students or $42.11 \%$. Score interval between 75 to 100 obtained by 22 students or $57.89 \%$. In cycle 2, cognitive competence of students increased. Although increasing, the competence of the student has not been achieved, as a minimum score of 75 has not reached $75 \%$ of the number of students.

In cycle 3, the acquisition of cognitive competency test scores of students in the interval between 0 and 74 are 9 students or by $23.68 \%$. Score interval between 75 to 100 obtained by 29 students or $76.32 \%$. At this cycle, cognitive competence of students has increased and has gained achievement of student competence. That is, learning subjects Building Materials Lab has achieved the expected results because more than $75 \%$ of the students have achieved a minimum score of 75 .

\section{Psychomotor Competence Students at the Implementation of Problem Based Instruction}

Indicators of successful learning courses for the Building Materials Laboratory psychomotor competency can be achieved when $75 \%$ of all students obtained a score of at least 75. Acquisition of competence psychomotor from cycle to cycle is a cycle 1 has increased by $55.26 \%$, amounting to $68.42 \%$ cycle 2 , cycle 3 amounted to $78.95 \%$.

In cycle 1 , the acquisition of psychomotor competency test scores of students in the interval between 0 and 74 there are 17 students or $44.74 \%$. Score interval between 75 to 100 obtained by 21 students or $55.26 \%$. This means that in cycle 1 , psychomotor competency in subjects Lab Building Materials through PBI has not been achieved, because at least $75 \%$ of the students have not reached the score of 75 . Deficiencies in student learning activities and teaching faculty contained in one cycle into consideration to make improvements in cycle 2 .

In cycle 2 , the acquisition psychomotor competency test scores of students in the interval between 0 and 74 there are 12 students or by $31.58 \%$. Score interval between 75 to 100 obtained by 26 students or by $68.42 \%$. At this cycle, psychomotor competencies increased, but has not reached the targeted competencies obtain a minimum score of 75 has not reached $75 \%$ of the number of students.

In cycle 3 , the acquisition psychomotor competency test scores of students in the interval between 0 to 74 are 8 students or by $21.05 \%$. Score interval between 75 to 100 obtained by 30 students or by $78.95 \%$. At this cycle, psychomotor competencies have increased and have acquired student achievement of competence. That is, learning subjects Building Materials Lab has achieved the expected results because more than $75 \%$ of the number of students has reached a score of $\min .75$.

\section{Affective Competence Students At The implementation of Problem Based Instruction}

Affective competencies measured obtained from the observation sheets with scale $(1=$ very negative; $2=$ negative; 3 = moderate; 4 = positive; $5=$ very positive) were carried out on each cycle of learning. Indicators of successful learning course Lab Building Materials for the affective aspect can be achieved when $75 \%$ of all students obtained a score of at least 4. Acquisition of affective competencies of students in cycle 1 at $60.53 \%$, at $71.05 \%$ for cycle 2 and cycle 3 of $81,58 \%$.

In cycle 1 , the acquisition of affective competency test scores of students on a scale between 1 and 3 there are 15 students or by $39.47 \%$. The scale of between 4 to 5 obtained by 23 students or by $60.53 \%$. This means that in cycle 1 , affective competence in the subjects Building Materials Lab through PBI has not been achieved, because at least $75 \%$ of the students have not reached the minimum scale 4 . Deficiencies in student learning activities and teaching faculty contained in one cycle into consideration to make improvements in cycle 2 .

In cycle 2 , the acquisition of affective competency test scores of students on a scale between 1 and 3 there are 11 students or by $28.95 \%$. The scale of between 4 to 5 obtained by 27 students, or by $71.05 \%$. This means that in cycle 1 , affective competence in the subjects Building Materials Lab through PBI has not been achieved, because at least $75 \%$ of the students have not reached the minimum scale 4 .

In cycle 3 , the acquisition of affective competency test scores of students on a scale between 1 and 3 there are 7 students or by $18.42 \%$. The scale of between 4 to 5 obtained by 31 students or by $81.58 \%$. At this cycle, affective competencies students have increased and have obtained the expected results because more than $75 \%$ of the number of students has reached a scale at least 4.

\section{Management of Problem Based Instruction}

Based on observation, teachers can manage the Problem Based Instruction in the class well. Management activities include introductory, core activities, closing, time management and classroom atmosphere. Lecturer to motivate student learning objectives and deliver increased from the first cycle to the last cycle. This is done better from cycle to cycle for granting the initial motivation is very necessary so that students are motivated to learn. Was the initial motivation always connect with prior knowledge.

This improvement not only on the motivation and presents the objectives, but also on core activities, cover and manage classroom atmosphere. For time management has done well, because the teacher allocates the same time at each meeting. Learning good management of a positive impact on student competence and can achieve the desired objectives. This leads to the competencies achieved by students on student competency tests. Thus the implementation of Problem Based Instruction in the subject of Building Materials Laboratory has performed well and has a positive impact on students' competencies.

\section{CONCLUSIONS}

Based on the results of Class Action Research concluded: "Application Problem Based Instruction on laboratory course building materials appropriately, can improve cognitive 
competence, competence psychomotor, and affective competencies of students of Technical Education Building, Civil Engineering Department, Faculty of Engineering Unesa"

A. Cognitive competence of students has increased from cycle to cycle and have acquired student achievement of competence. That is, Problem Based Instruction on building materials laboratory's course can improve cognitive competencies expected because most of the students have achieved the maximum score of appropriate standardized tests

B. Psychomotor competency of students has increased from cycle to cycle and have acquired student achievement of competence. That is, Problem Based Instruction on building materials laboratory's course can improve psychomotor competencies expected because most of the students have achieved maximum performance scores were standardized.

C. Affective competencies of students has increased from cycle to cycle and have acquired student achievement of competence. That is, Problem Based Instruction on laboratory course building materials can increase affective competencies as expected because most of the students have reached the maximum standardized scale affection,

\section{REFERENCES}

[1] Gagne, RM. and Leslie J. Briggs., Principles of Instuctional Design. New York: Prentice Hall Inc. Helda Taba and Elizabeth Noel, Steeps in the Action Research in the Action Research Reeder (Victoria Australia: Deakin University) 1979, p. 67.

[2] Jackson, N., Civil Engineering Materials. Hongkong: ELB \& MacMillan, 1978.

[3] Kember, David, Action Learning and Action Research. USA: Kogan Page Limited, 2000.

[4] Nur, Mohamad, Problem Based Teaching. University Press: UNESA, 2000 .

[5] Nur, Mohamad, Learning Strategies. Surabaya: Center for Science \& Mathematics School, 2004.

[6] Nasution, Andi Hakim, The Leaves were Scattered. Jakarta: Sarana Inti Script, 1975.

[7] PGSM, Project Training Team, The Class Action Research. Jakarta: Directorate General of Higher Education Development Project of Secondary Teachers of Education, 1999, p. 8.

[8] Research Team Project, Classroom action research. Jakarta: Derjen Higher Education, 1999.

[9] Ringsun, I Nyoman, Material Science. Surabaya: Unesa, 2004.

[10] Rooijakkers, Ad., Teaching With Success. Jakarta: Grasindo, 1991.

[11] Singh, G., Materials of Construction. Delhi: Standard Book Service, 1979.

[12] Wardadani, I.G.A.K., et al., Class Action Research. Jakarta: Univ. Open, 2000. 